\title{
Numerical Prediction and Field Verification Test of Wind-Power Generation Potential in Nearshore Area Using a Moored Floating Platform
}

\author{
Koichi Watanabe, Yuji Ohya, Takanori Uchida, Takashi Karasudani, Tomoyuki Nagai \\ Research Institute for Applied Mechanics, Kyushu University, Fukuoka, Japan \\ Email: koichi-watanabe@riam.kyushu-u.ac.jp
}

How to cite this paper: Watanabe, K., Ohya, Y., Uchida, T., Karasudani, T. and Nagai, T. (2017) Numerical Prediction and Field Verification Test of Wind-Power Generation Potential in Nearshore Area Using a Moored Floating Platform. Journal of Flow Control, Measurement \& Visualization, 5, 21-35.

https://doi.org/10.4236/jfcmv.2017.52002

Received: November 7, 2016

Accepted: March 28, 2017

Published: March 31, 2017

Copyright $\odot 2017$ by authors and Scientific Research Publishing Inc. This work is licensed under the Creative Commons Attribution International License (CC BY 4.0).

http://creativecommons.org/licenses/by/4.0/ (c) (i) Open Access

\begin{abstract}
The offshore turbine system was installed on a floating platform moored in Hakata Bay, offshore of Fukuoka, Japan. An identical turbine system was also installed at the adjacent waterfront. The separation of the two turbines was 3.7 $\mathrm{km}$. Wind flow tends to be more stable and the average wind speed is often larger in offshore areas than adjacent land areas at typical wind turbine hub height. This study focused on the wind condition of a nearshore area to clarify the advantages of nearshore wind farming. Prior to field experiment, wind conditions were predicted by using numerical simulation. It is useful for estimating topographical effect in nearshore areas. Next, field verification test was done by directly comparing wind data obtained from the identical wind turbine systems installed at an offshore location and the adjacent waterfront over the same extended period. The corresponding power output of these turbines was also compared. The data set exhibits $23 \%$ larger annual average wind speed at the offshore location and smaller turbulent intensity, resulting doubled annual power production.
\end{abstract}

\section{Keywords}

Wind Turbine, Nearshore, Floating Platform, Wind Lens, Field Experiment, CFD

\section{Introduction}

One of the main motivations for installing wind farms in offshore areas is the higher wind speed, which increases the capacity factor. As often seen in European countries such as the United Kingdom, Denmark, Germany, and the Neth- 
erlands, the majority of recently installed and currently planned offshore windfarms are located in areas with water depths shallow enough for solid foundations, at distances of at least $5 \mathrm{~km}$ from the adjacent shore. In some cases, the installations have been located at distances of more than $20 \mathrm{~km}$ from the shore, to exploit the higher average wind speed. In Japan, it is also generally true that wind conditions improve further from the shore, as can be seen on the local area wind prediction map of the New Energy and Industrial Technology Development Organization (data are $30 \mathrm{~m}$ above the surface with $5 \times 5 \mathrm{~km}$ grid resolution) [1] [2]. However, in Japan which has steep submarine terrains, it is rather difficult to find suitable offshore areas similar to the European examples. Moreover, energy transfer costs via undersea cables are very high. Therefore, constructions of offshore wind farms with large distances from the shore are often uneconomic. This study focuses on the wind potential of relatively nearby offshore areas.

In the case of Japanese wind conditions, areas with appropriate wind conditions are limited and often situated in remote mountainous areas where access is difficult or along the coastline [1] [2]. The total area of Japan's territorial waters and exclusive economic zone, and the total length of the coastline are both the sixth largest in the world. However, the typical average annual wind speed in most shore areas of Japan is about $4-5 \mathrm{~m} / \mathrm{s}$ at a height of $30 \mathrm{~m}$ above ground, which means that paying off the initial investment on a wind farm would not be easy, even when benefitting from the current Feed-in Tariff on wind power. In areas only about $1 \mathrm{~km}$ from the shore, the average wind speed often increases by about $25 \%$, which potentially doubles both the power output of wind turbines and the capacity factor. This situation appears to hold in Fukuoka, Japan where this experiment was conducted [1] [2].

In this study, characteristics of the wind such as the speed and the turbulence intensity were compared between a near offshore and an adjacent shore area in Japan. Additionally, the corresponding power production of two identical small wind turbines installed at these locations was compared. This study was undertaken to clarify the differences in wind conditions between near offshore areas and neighboring shore areas to develop understanding of the advantages and disadvantages of wind farming in offshore locations, even when at relatively short distances from the adjacent shore. Before proceeding in this project, wind conditions were predicted and a site for wind-power generation in near offshore area was chosen by using numerical simulations of the wind flow. Accordingly, a land-based turbine was installed in Minato Park in Fukuoka city, Japan. Near offshore data were obtained from a turbine on a floating platform installed in Hakata Bay, offshore of Fukuoka. The separation between the two turbines was only $3.7 \mathrm{~km}$. The installed turbines were Wind-Lens turbines (see Figure 1), which are a new type of ducted high efficiency turbine developed in our laboratory at Kyushu University [3]. This study takes the initiative of development acts for wind-power generation in near offshore area, i.e., numerical prediction of wind conditions, measurements of actual wind data, and power generation test 


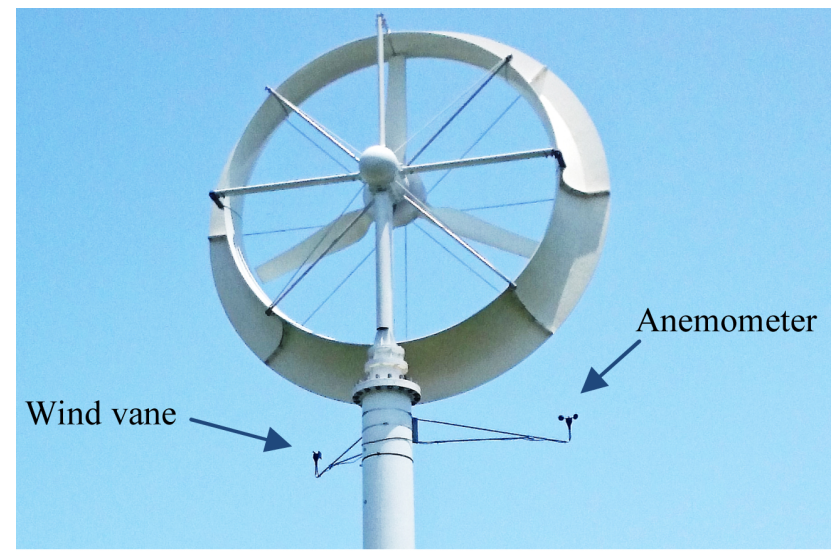

Figure 1. Wind-Lens turbine.

of wind turbine in near offshore area.

\section{Predictions of Wind Conditions and Choice of a Site for Wind-Power Generation in Near Offshore}

Prior to field experiment, a number of locations suitable for the installation of a small wind turbine along the waterfront of Fukuoka (in the Kyushu island in the south of Japan) were identified using the RIAM-COMPACT micro-siting software [4]. Currently, a commercial version is widely used by many private companies and governmental agencies. The core solver employs a large-eddy simulation and it is capable of analyzing complex flows with horizontal resolution as fine as $2 \times 2 \mathrm{~m}$.

The list of selected sites included Minato Park (red dot in Figure 2) and several other locations near the mouths of the rivers in Fukuoka. An offshore location for the experimental floating platform (yellow dot in Figure 2) was selected near Minato Park for comparison purposes, which avoided restricted areas set by the local fisheries union and the authorities of the city of Fukuoka, and the port of Hakata. The floating platform was located $3.7 \mathrm{~km}$ from the park and about $800 \mathrm{~m}$ off the nearest shore.

\subsection{Predictions of Average Wind Speed and Direction in Near Offshore}

There were two Grid Point Value (GPV) data points near the selected locations (green dots in Figure 2), which allowed us to estimate the annual average wind speeds of these areas. The GPV archive, which is maintained by the Japan Meteorological Agency, provides daily operational weather forecasting data. The data sets were produced using numerical simulation models that included the global spectral model, regional spectral model, and mesoscale nonhydrostatic model. The grid resolution of the model is $5 \times 5 \mathrm{~km}$ and it has good coverage of Japan's coastline. The data sets are archived and maintained by Tsukuba University Center for Computational Sciences and they are available through the Japan Meteorological Business Support Center and Kyoto University [5] [6] for academic use. The annual average wind speeds extracted from GPV data for 2011 


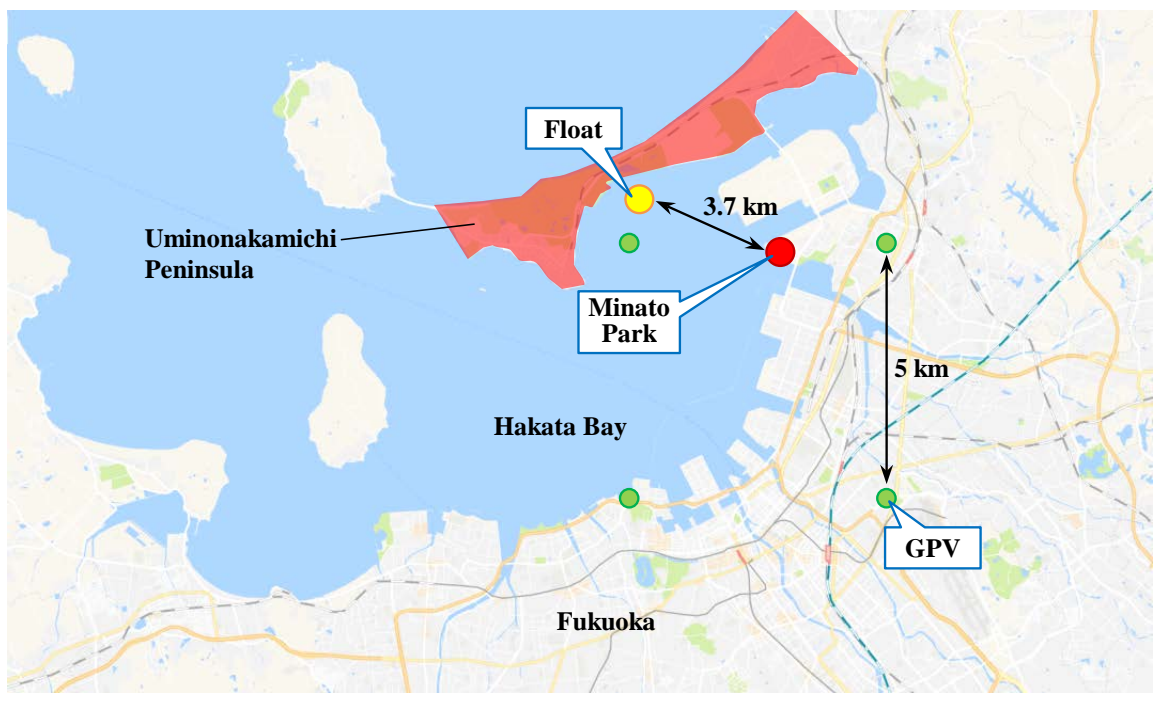

Figure 2. Map showing grid point values near Fukuoka center (indicated by green dots, separations are $5 \mathrm{~km}$ ), Minato Park (red dot), and experimental floating platform (yellow dot).

are $3.0 \mathrm{~m} / \mathrm{s}$ and $4.7 \mathrm{~m} / \mathrm{s}$ for the grid points near Minato Park and the floating platform, respectively. These wind speeds are at $10 \mathrm{~m}$ above the surface. The actual location of the park is much closer to the water than the GPV point; thus, the actual average wind speed at Minato Park is expected to be higher than this value. We estimated the difference in the wind speed between the floating platform and the park to be around $1 \mathrm{~m} / \mathrm{s}$, which was considered suitable for the purposes of the experiment.

Figure 3 shows the average wind speed and wind direction occurrence for each wind direction bin obtained from the GPV point closest to the float location. One of the dominant wind directions resolved by the GPV was northnorthwest, and the average wind speed was about $6 \mathrm{~m} / \mathrm{s}$. As shown in Figure 2, the wind direction coincided with the direction of the closest land area, i.e., Uminonakamichi Peninsula. Although the elevation of this stretch of land is well below $10 \mathrm{~m}$ and no large buildings or structures exist in that direction, we considered that the topographical effect should be estimated.

\subsection{Predictions of Topographical Effect in Nearshore Areas}

The wind flowing across the peninsula was simulated using the RIAMCOMPACT software to clarify that there was no major reduction in the wind speed, especially at the height of the turbine hub ( $10 \mathrm{~m}$ above sea level). Figure 4 shows the computational grid of a middle scale simulation. The number of grid points is $201 \times 301 \times 41$. The grid spacing is $100 \mathrm{~m}$ and equidistant in horizontal directions. In vertical direction, the grid spacing is $0.5 \mathrm{~m}$ at the bottom of the simulated area and is enlarged in vertical direction. The spacings are small near the surface to simulate the atmospheric boundary layer. The results shown in Figure 5 illustrate top view of distributions of the streamwise velocity component. No major reduction in the wind speed estimated around the peninsula. 


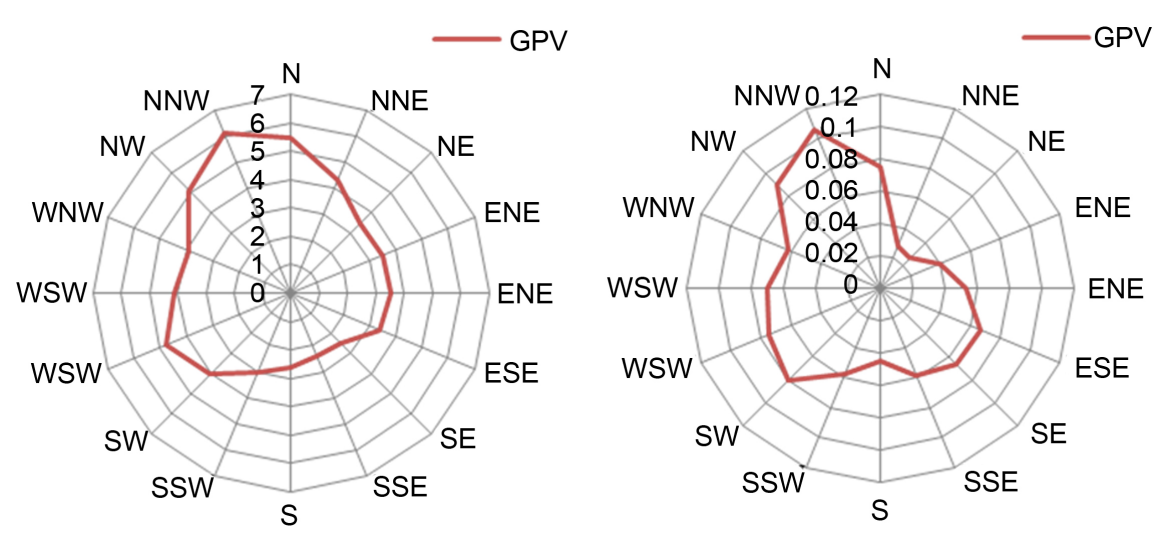

Figure 3. Wind rose at the GPV point near the experimental site. Radial axis is the average wind speed $(\mathrm{m} / \mathrm{s})$ (left) and rate of occurrence (right).

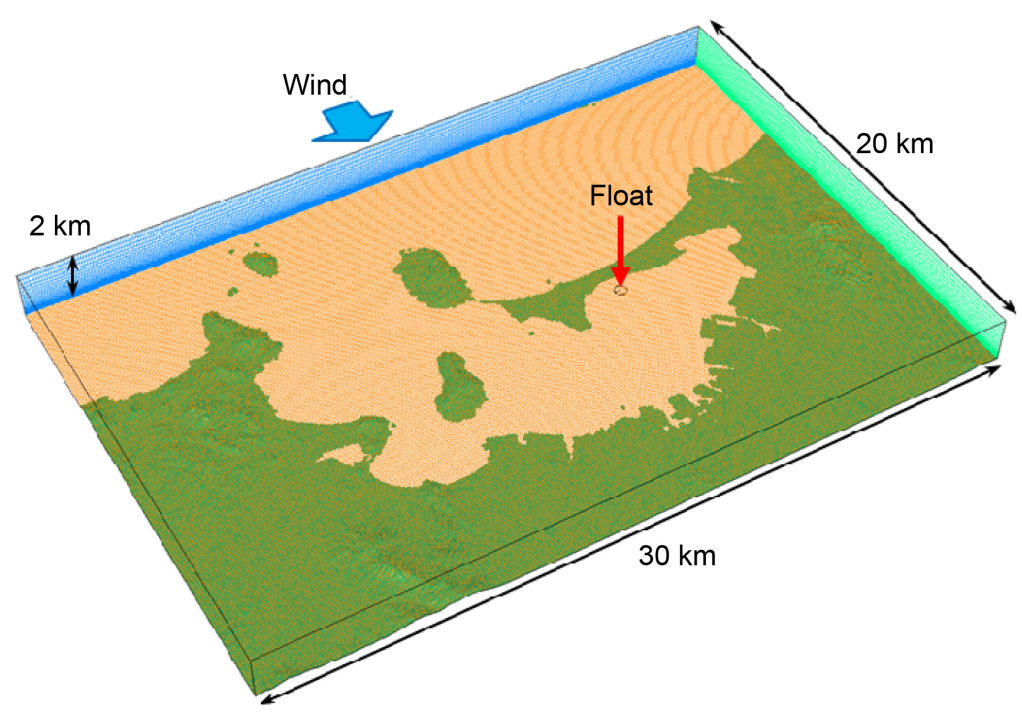

Figure 4. Computational grid of a middle scale simulation.

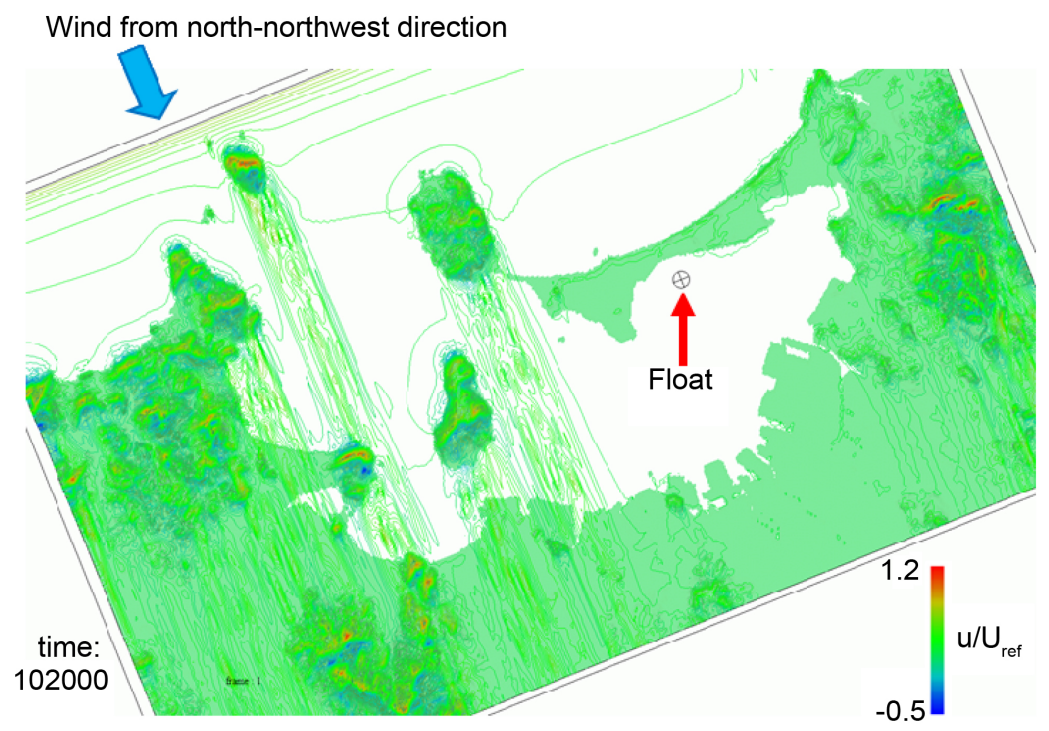

Figure 5. Top view of distributions of the streamwise velocity component (middle scale simulation). 
Furthermore, small scale wind conditions were simulated next. Figure 6 shows the computational grid of a small scale simulation. The number of grid points is $101 \times 226 \times 41$. The grid spacing is $40 \mathrm{~m}$ and equidistant in horizontal directions. In vertical direction, the grid spacing is $0.5 \mathrm{~m}$ at the bottom of the simulated area and is enlarged in vertical direction. Figure 7 illustrates top view of distributions of the streamwise velocity component. The wind conditions around the float location were hardly affected by topographical effect. The results shown in Figure 8 illustrate the wind vector plot and the vertical wind profile. In the plot, the vertical axis represents the height above sea level, and the horizontal axis represents the normalized average wind speed. The profile was smooth and without major deficit at any height.

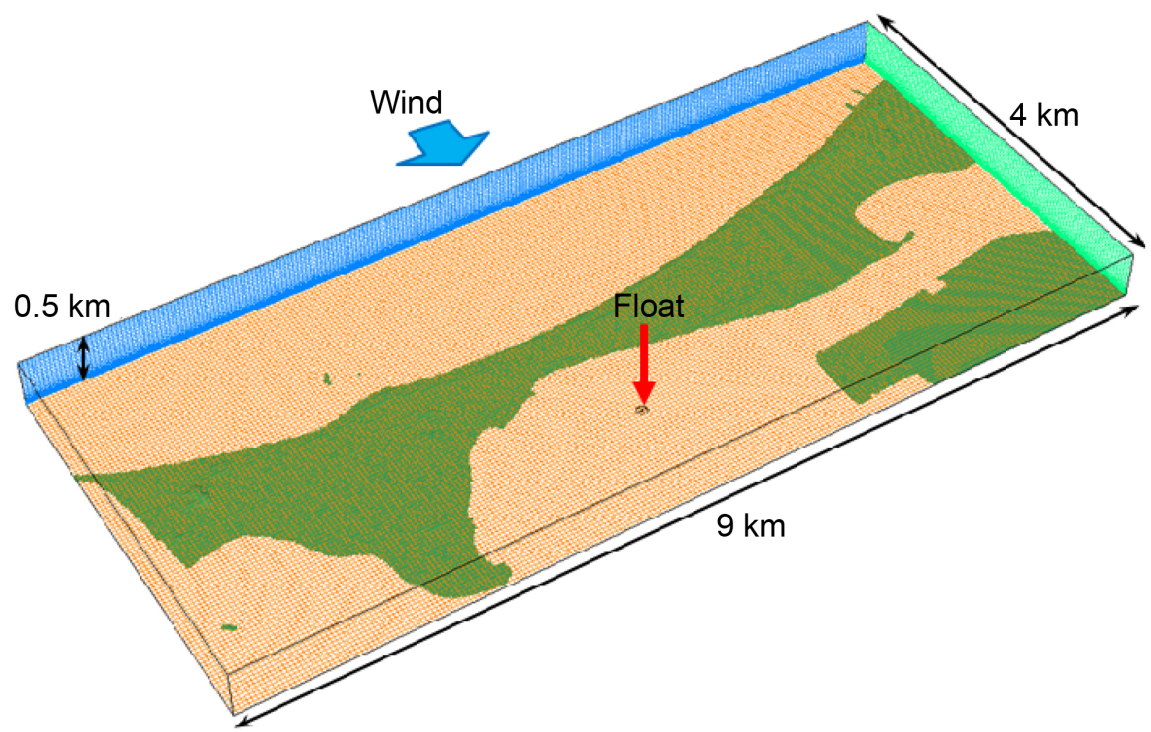

Figure 6. Computational grid of a small scale simulation.

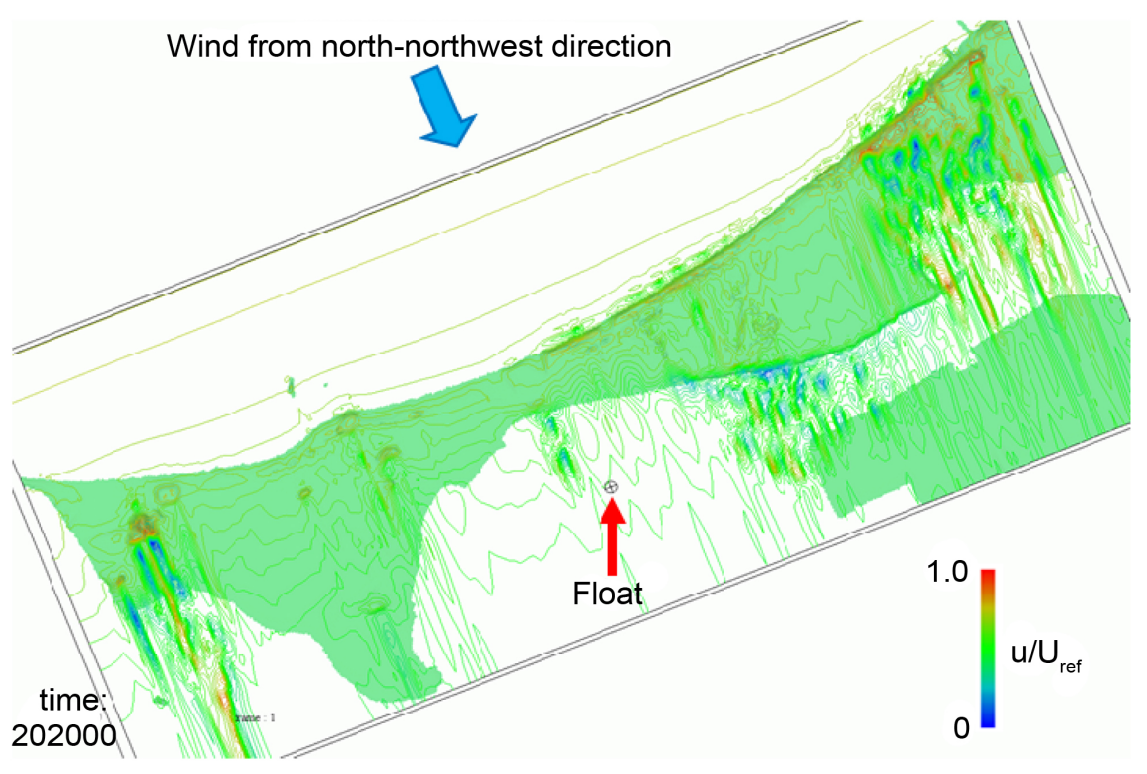

Figure 7. Top view of distributions of the streamwise velocity component (small scale simulation). 


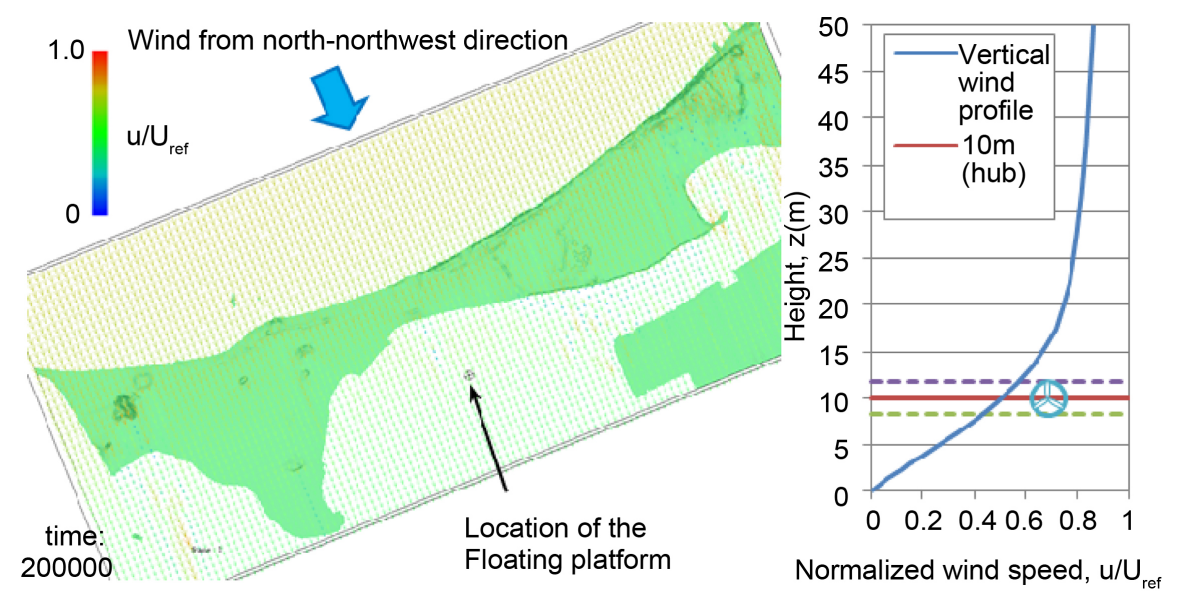

Figure 8. Wind vector plot of RIAM-COMPACT simulated and calculated vertical wind profiles at the experimental site. Hub height and the size of the turbine are indicated in the plot.

\section{Field Experiments in Near Offshore and Adjacent Land Areas}

After the wind predictions, we undertook a field verification test using a moored floating platform. The floating platform for this experiment consisted of six hollow prestressed concrete columns connected in a hexagonal shape by concrete truss bridges (Figure 9 and Figure 10). The height of each column was $4 \mathrm{~m}$ and the draft of the float was designed to be $2.4 \mathrm{~m}$. The largest dimension of the hexagon spanned $18 \mathrm{~m}$, as shown in Figure 10. The total mass of 140 tons, including the platform (130 tons), turbines and their support structure, and an array of rechargeable batteries and other components, was moored by six nylon cables (45-mm diameter) with middle-sinkers, making it semisubmersible for adequate stability against extreme local wave and wind conditions [7]. Each cable was anchored by a 20-ton block. The extreme local wave and wind conditions associated with a return period of 30 years were taken into account for the design of the float and mooring through scaled model experiments and numerical simulations. The final design constrained the maximum roll and yaw angles of the float to less than $5^{\circ}$ [7] to keep the inclined deck of the platform above the water. Together with two 3-kW Wind-Lens turbines, $2-\mathrm{kW}$ PV panels were installed as part of the hybrid power generation system. The turbine hub height was set to approximately $10 \mathrm{~m}$ above sea level. The total rated output power of the experimental system was $8 \mathrm{~kW}$. The platform construction was completed in November 2011. After installation of the power generation system and related safety parts, the platform was launched on December 4, 2011, following which it was towed to the mooring site $800 \mathrm{~m}$ off the adjacent shoreline (Figure 2).

In September 2012, the northern Kyushu area was hit by large typhoons with maximum wind speeds of larger than $50 \mathrm{~m} / \mathrm{s}$. During the typhoons, the roll and yaw angles of the float were successfully constrained within the designed specification [7]. The recorded maximum cable tension was less than 8 tons, which was well under the maximum yield tension (31 tons) for each cable [7]. According 


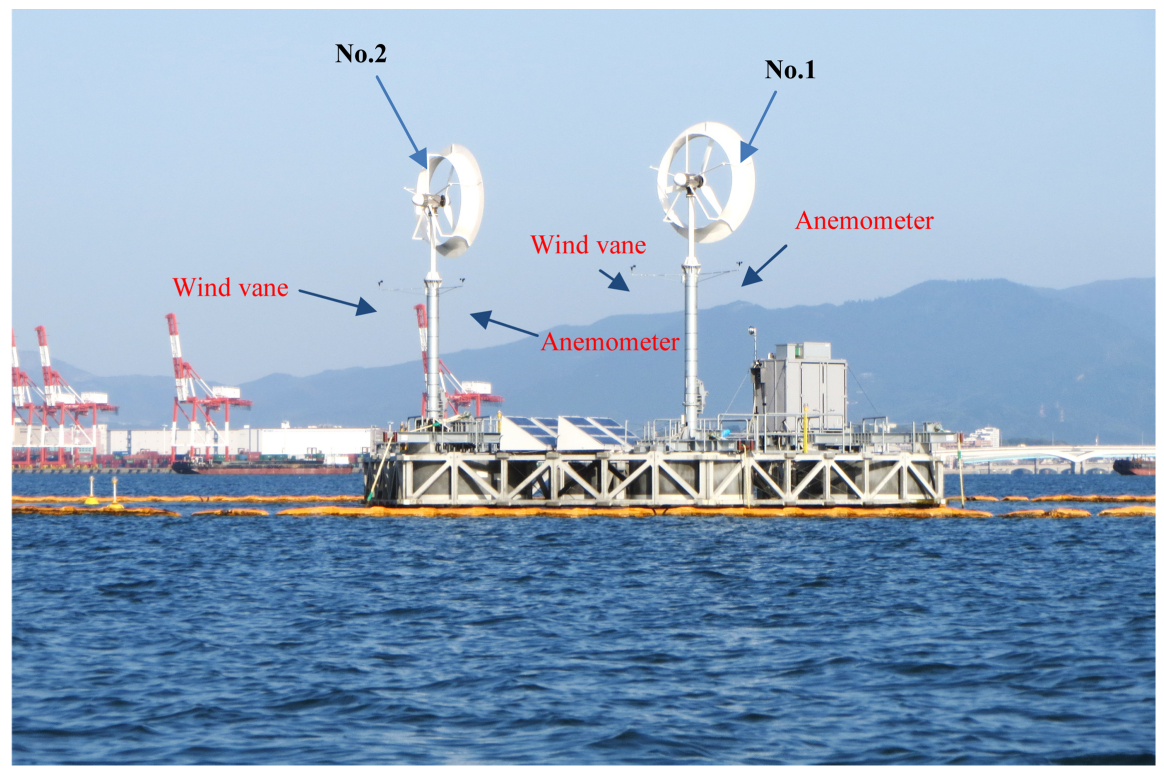

Figure 9. Floating platform and turbines installed in Hakata Bay.

to $\mathrm{Hu}[8]$, the present floating body was expected to be safe against the severe sea conditions which appear in the winter season in Japan sea.

\subsection{Measurements of Wind Speed and Turbulence Intensity}

Figure 11 shows the average wind speed and wind direction occurrence for each wind direction bin obtained from the GPV point closest to the float location (solid lines) and the actual data obtained at the floating platform (dotted lines) for comparison. An anemometer (RNRG 40C; cup anemometer) and wind vane (RNRG 200P) were equipped with each turbine for wind data acquisition as shown in Figure 9. These wind sensors were installed $2 \mathrm{~m}$ lower than the hub and $1.7 \mathrm{~m}$ from the center of the tower (in Figure 10, the positions of the wind vanes are indicated by blue squares and positions of the anemometers are indicated by green stars). Note, the hub height of the turbine in Minato Park was approximately $15 \mathrm{~m}$ above sea level, and the relative locations of the wind sensors to the hub were the same as on the floating platform. The average wind speed agreed rather well with numerical prediction. As for rate of occurrence, the wind from east direction observed more frequently than it was estimated.

Figure 12 shows a comparison of the monthly averaged wind speeds at the floating platform and at Minato Park between November 2012 and October 2013 (data points are missing for April, May, and September 2013 because of turbine maintenance). Average wind speeds at the float for each month exceeded those at Minato Park. This tendency continued throughout the 1-year monitoring period. The average wind speeds over the entire period at the park and at the float were 3.5 and $4.3 \mathrm{~m} / \mathrm{s}$, respectively. These values generally agreed with the estimates extracted from the GPV data set. The wind speed histogram obtained from this experiment at each location obeyed the Rayleigh distribution well, as shown in Figure 13. 


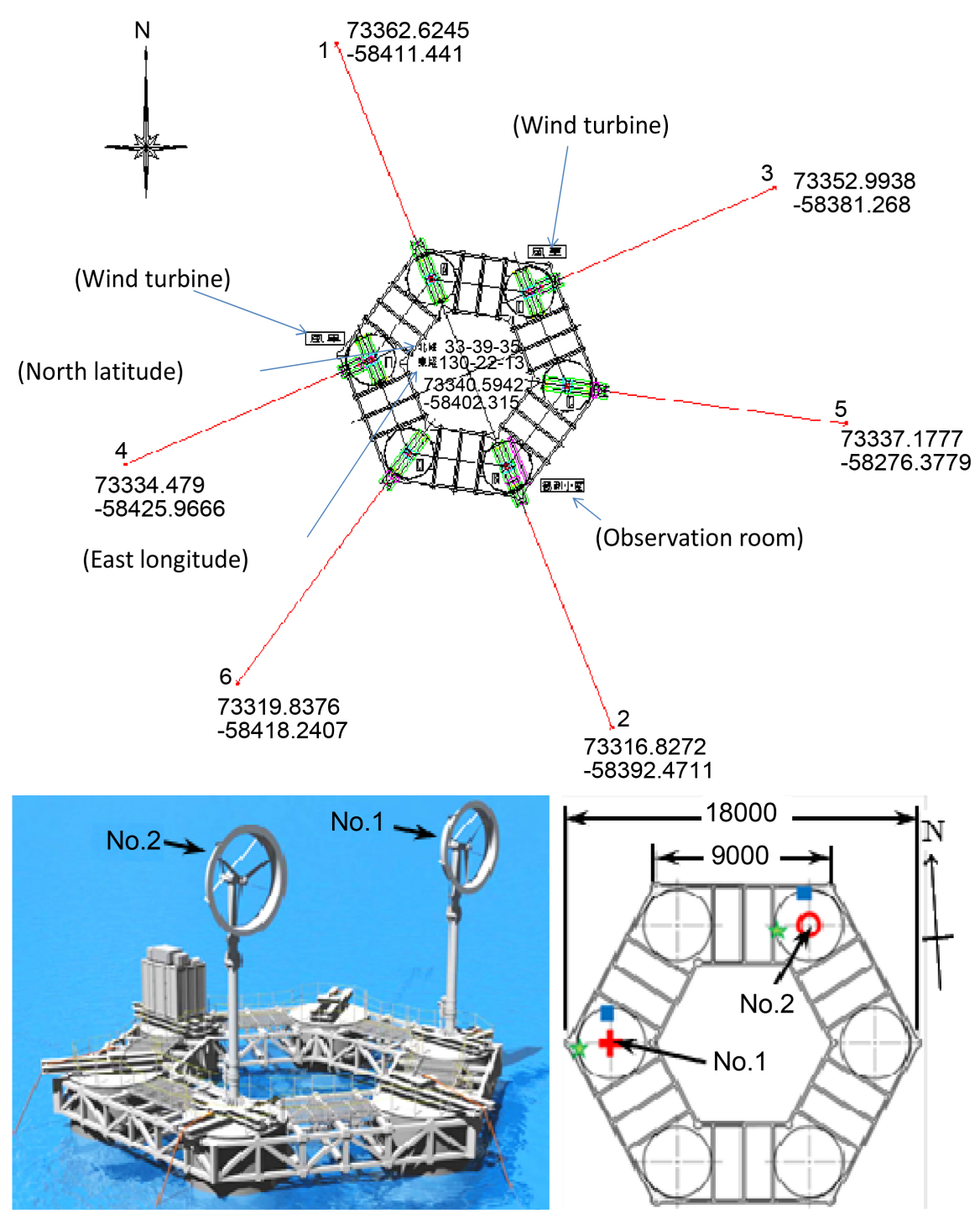

Figure 10. Mooring schematic and dimensions of the platform. The red circle indicates the location of the turbine used for this study and the red cross indicates the position of another identical turbine (right).

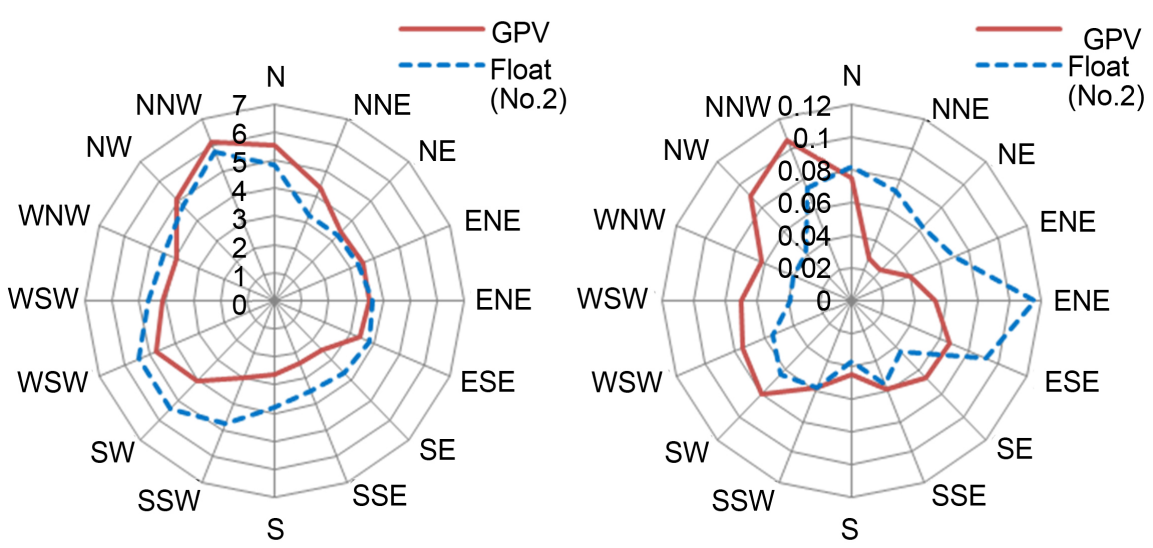

Figure 11. Wind rose at the GPV point near the experimental site (solid line) and actual Nov. 2012-Oct. 2013 data from the offshore experimental site (dotted line). Radial axis is the average wind speed $(\mathrm{m} / \mathrm{s})$ (left) and rate of occurrence (right). 


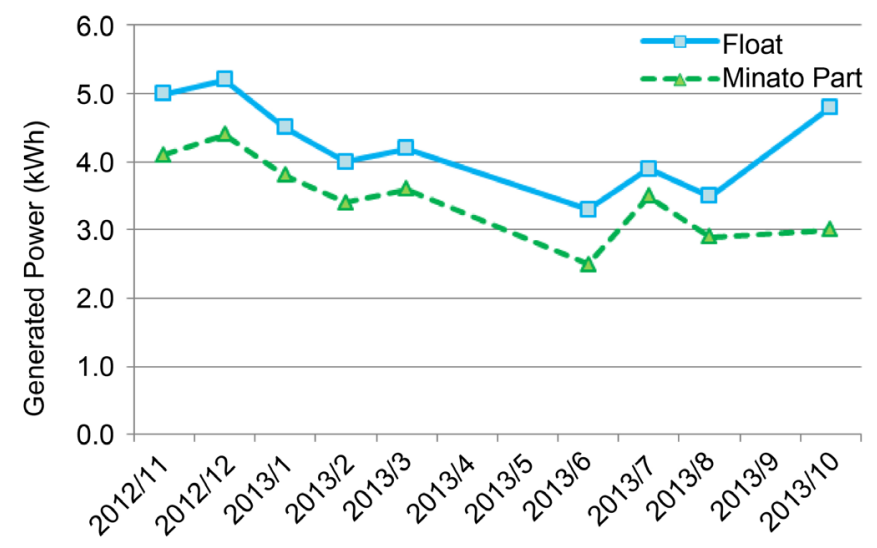

Figure12. Monthly average wind speed at Minato Park and at the floating platform.
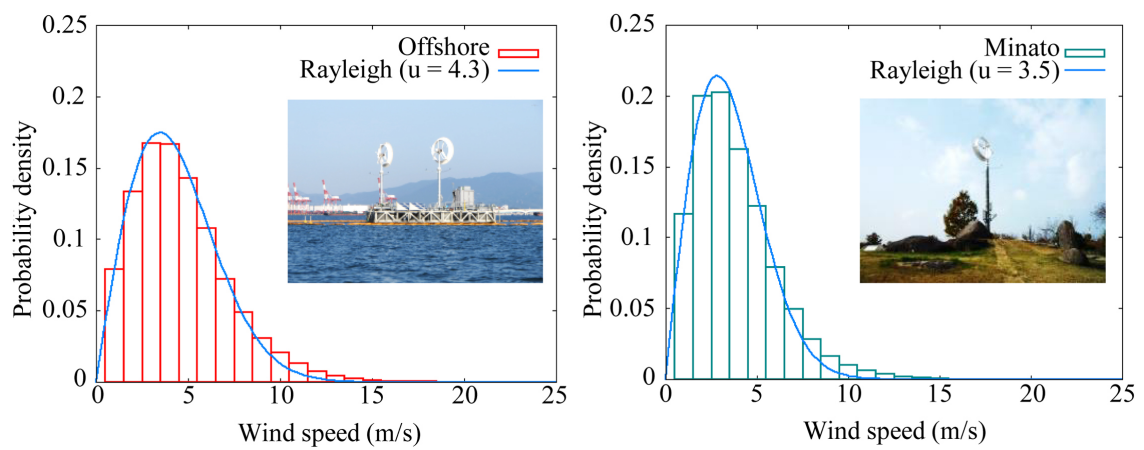

Figure 13. Wind speed histogram at the float (left) and at Minato Park (right). They are plotted with Rayleigh distributions, where $\mathrm{u}$ is the corresponding average wind speed.

Turbulence intensity highlights the clear difference between the wind characteristics of the offshore and adjacent onshore locations (Figure 14 and Figure 15). Here, the turbulence intensity was defined as the standard deviation of wind speed over $10 \mathrm{~min}$, divided by the average wind speed over the same period at the same location. As expected, the turbulence intensity at the float was clearly smaller than at the park over the entire range of wind speeds of turbine operation (larger than $3 \mathrm{~m} / \mathrm{s}$ ). Typical turbulence intensity over offshore areas near land can be estimated using a surface roughness parameter calculated by the Charnock expression [9] [10]. The estimated surface turbulence intensity over sea near the coast is 0.12 at a wind speed of $10 \mathrm{~m} / \mathrm{s}$ for a hub height of $10 \mathrm{~m}$. The experimental value at the float was 0.14 on average and 0.16 with one standard deviation of the wind speed bin (bin center is $10 \mathrm{~m} / \mathrm{s}$ ) added. As shown in Figure 15, the turbulence intensity at the float was remarkably smaller than at Minato Park. In Figure 15, IEC standard turbulence classes of A, B, and C are also plotted. The turbulence intensity at the float is as low as class $\mathrm{C}$ which is defined as low turbulence intensity category in IEC 61400-1. The turbulence intensity at the float is also plotted for each wind direction in Figure 16. Larger turbulence was not found in the north and northwest directions (the direction of the adjacent peninsula) compared with the other directions. The turbulence seemed to 

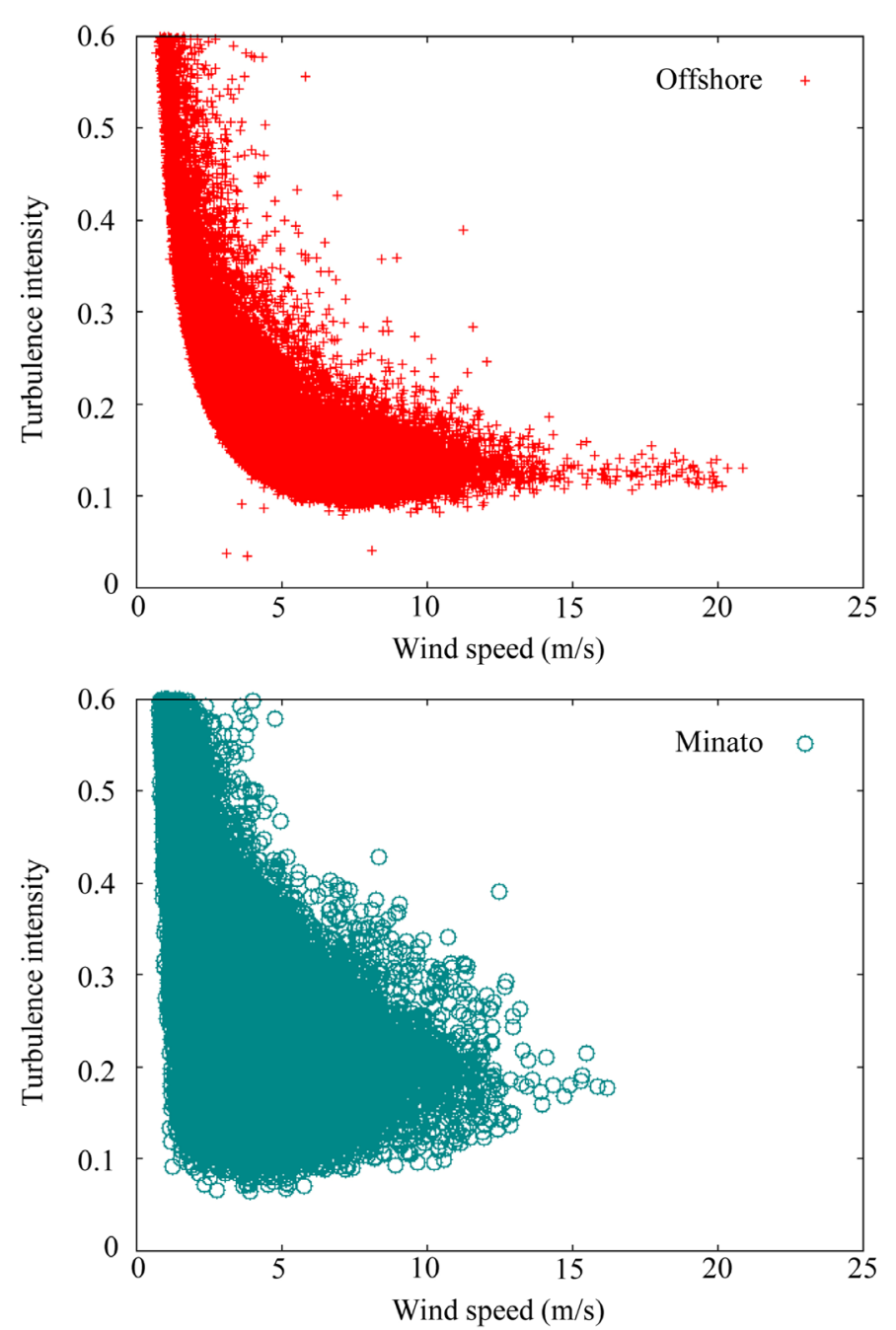

Figure 14. Turbulence intensity at the float (top) and at Minato Park (bottom).

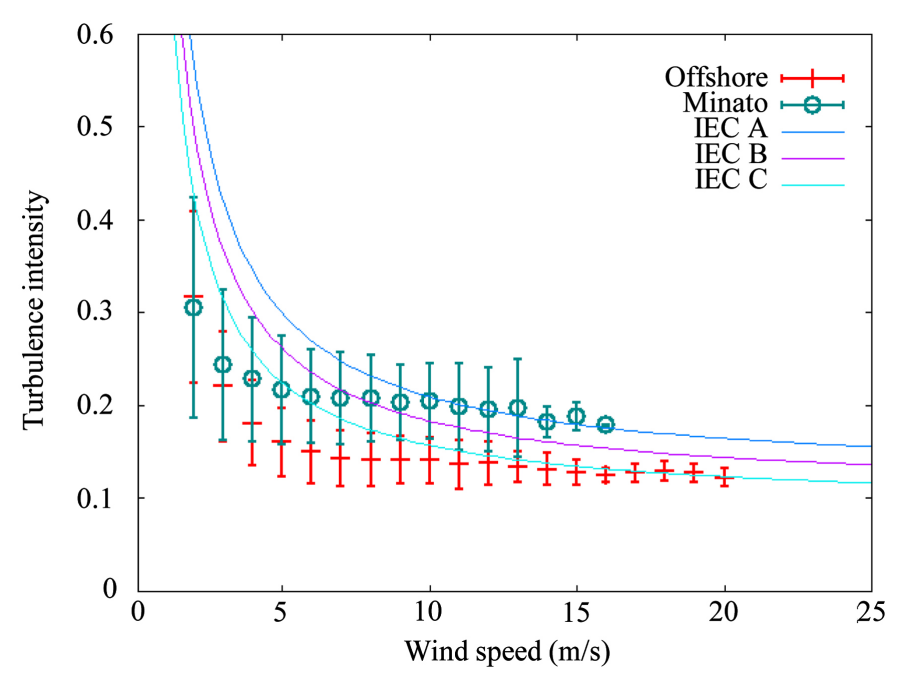

Figure 15. Comparison of the turbulence intensities (error bars showing $\pm 1 \sigma$ ). IEC standard turbulence classes of $\mathrm{A}, \mathrm{B}$, and $\mathrm{C}$ are also plotted. 


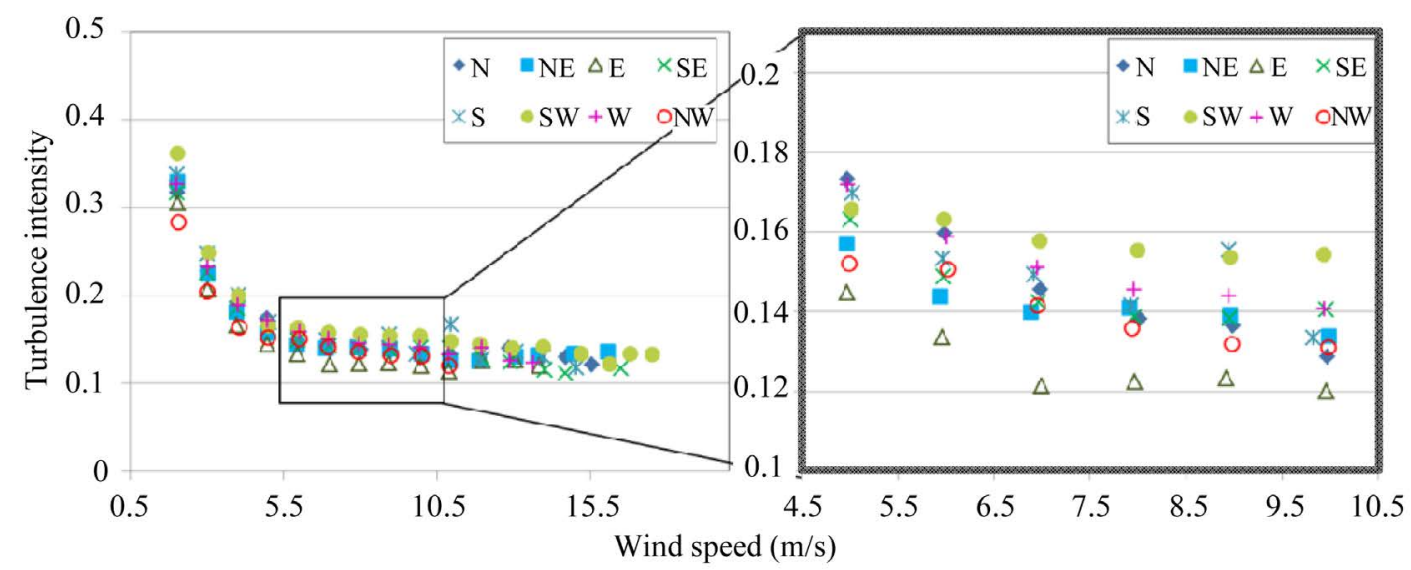

Figure 16. Turbulence intensity at the floating platform binned for each wind direction.

be generally higher in the southwest direction, which coincides with the direction of the other turbine on the platform, indicating a wake effect from the turbine, as shown in Figure 10. The separation between two turbines was $11.8 \mathrm{~m}$ (3.4 times the diameter of the shroud of wind turbine).

\subsection{Measurements of Wind-Power Generation}

The Wind-Lens turbine [3] is a highly efficient shrouded wind turbine developed at RIAM, Kyushu University. This shroud is designed to accelerate the incoming wind at the rotor by forming a strong vortex behind the device. This shroud also has the significant advantage of reducing blade-tip noise [11] [12] from the rotor by the canceling of the longitudinal blade-tip vortex by the vortex induced from the inner surface of the shroud [13] [14]. A typical power curve of the turbines used in this experiment is shown in Figure 17 with the field data. The field data agree rather well with the power curve. The deviation in the high wind speed region is caused by braking to protect the turbine from over-rotation during strong wind.

At a distance offshore of $3.7 \mathrm{~km}$, the average wind speed increases by about $0.8 \mathrm{~m} / \mathrm{s}$. This is a $23 \%$ increase compared with Minato Park. Consequently, as shown in Figure 18, the monthly power production at the offshore platform exceeded that at Minato Park in each month, as was expected (the high power appears on winter season because the seasonal wind blows in winter in Fukuoka, Japan. And, data points are missing for April, May, and September 2013 because of turbine maintenance). The average monthly power productions were 79 and $164 \mathrm{kWh}$ for Minato Park and the floating platform turbine, respectively. The resulting ratio of power production was 2.08 . The difference in average wind speed of just $0.8 \mathrm{~m} / \mathrm{s}$ doubled the power output, as was expected in this scenario.

\section{Conclusions}

This study focused on the wind potential of near offshore area as close as a few kilometers from the adjacent land. Numerical simulations of the approaching flow and field verification tests using wind turbine were undertaken to develop 


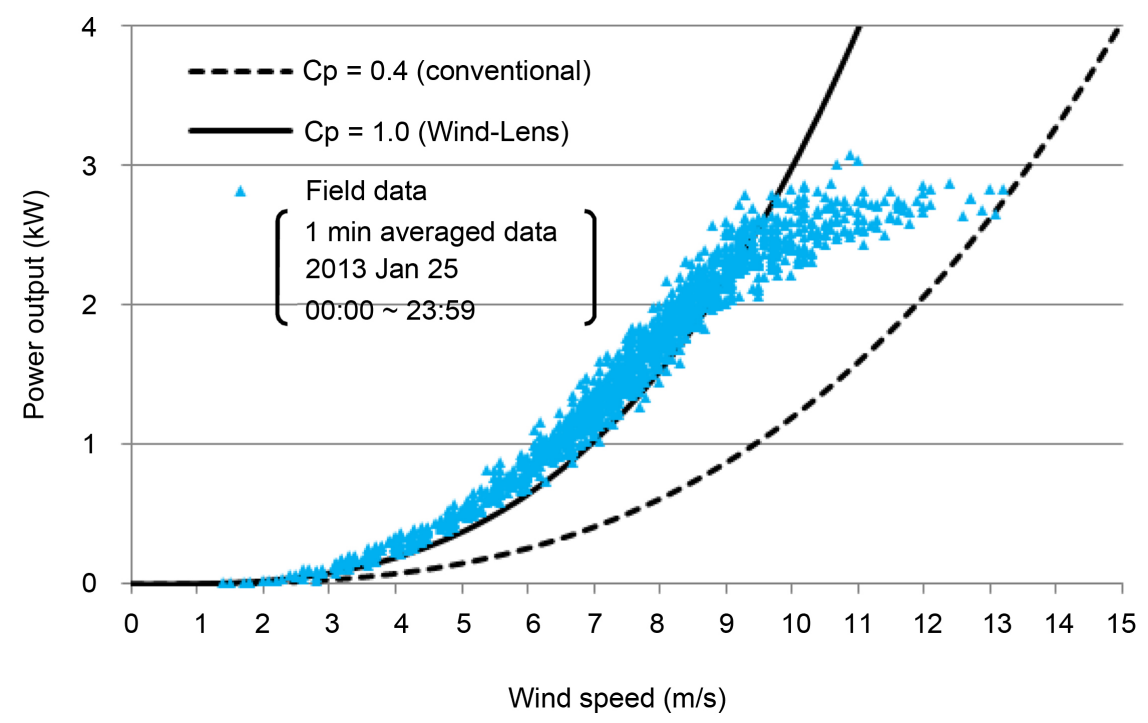

Figure 17. Power curve of the Wind-lens turbine on the float (data were obtained during the experimental period). The power coefficient $\mathrm{Cp}$ is calculated using the rotor radius.

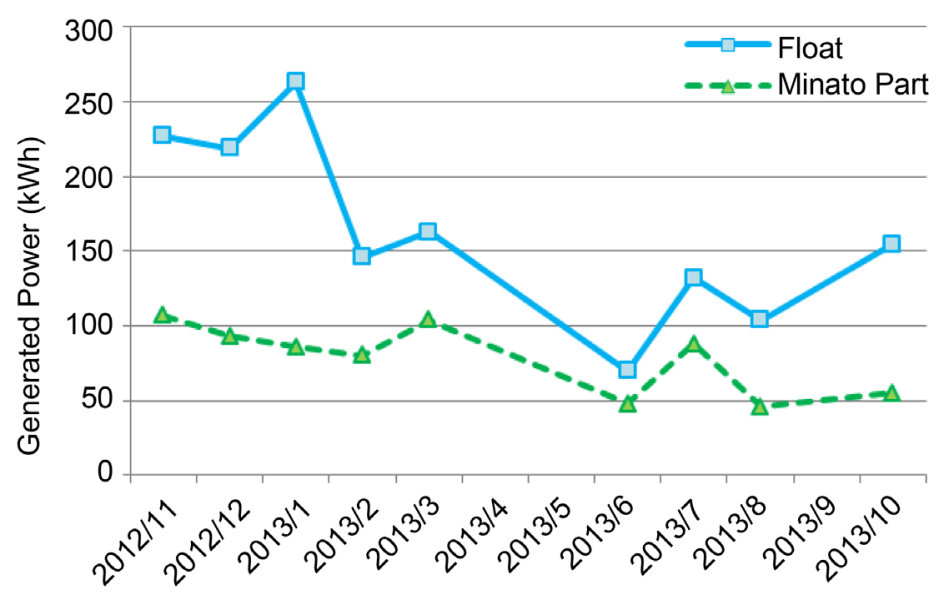

Figure 18. Power comparison between Minato Park and the floating platform.

understanding of the advantages of wind farming in offshore locations, even when at relatively short distances from the adjacent shore. This study took the initiative in wind-power generation in near offshore area, i.e., numerical prediction of wind conditions, measurements of actual wind data, and power generation test of wind turbine were conducted in near offshore area using a moored floating platform.

Prior to field experiment, a number of locations suitable for the installation of a small wind turbine along the waterfront were identified using the RIAMCOMPACT micro-siting software. It was estimated that the advantage in the wind speeds at $10 \mathrm{~m}$ above the surface of the nearshore ocean area compared to the adjacent shore to be around $1 \mathrm{~m} / \mathrm{s}$. As one of the dominant wind directions resolved by the GPV coincided with the direction of the closest land area, the topographical effect was estimated, but, numerical simulations in a couple of 
different resolutions predicted that no major reduction in the wind speed would appear around the near offshore area. After the predictions of wind conditions, field verification test was undertaken using a moored floating platform. Although a little difference was found in the rate of occurrence, the average wind speed agreed rather well with numerical prediction. The results of this field verification test declared that it is possible for us to predict wind conditions credibly by numerical simulation even if the simulated place is near offshore area where topographical effects occur easily and measurements of wind conditions over extended periods are difficult.

Additionally, the simultaneous wind observation at the ocean and the shore showed that the turbulence intensity at the near offshore area was clearly smaller than at the adjacent shore over the entire range of wind speeds of turbine operation. Furthermore, wind-power generation is measured at the both areas. The Wind-Lens turbine which is highly efficient shrouded wind turbines was applied to the experiments. As a matter of course, the wind turbine showed the ability at the near offshore area where the wind speed was high and the turbulence intensity was small. At the near offshore area, the average wind speed increases by about $0.8 \mathrm{~m} / \mathrm{s}$ and the resulting ratio of power production was 2.08 .

Although it is rather difficult to find suitable place in near offshore area, the results of this study suggested the economic feasibility of a nearshore wind farm because of the doubled capacity factor which was achieved by utilizing numerical simulation of the approaching flow. Therefore, wind power generations in the near offshore area using a floating structure could be one of the most feasible options for all the countries which have the steep submarine terrain.

\section{Acknowledgements}

This study was partially supported by the Ministry of the Environment, Japan. We gratefully acknowledge Kyushu University and our laboratory engineer Mr. Kimihiko Watanabe and Mr. Keiji Matsushima.

\section{References}

[1] NEDO Local Area Wind Prediction Map. http://app8.infoc.nedo.go.jp/nedo/index.html

[2] NEDO Wind Power Implementation Guidebook, 2008 Version. http://www.nedo.go.jp/library/fuuryoku/guidebook.html

[3] Ohya, Y. and Karasudani, T. (2010) A Shrouded Wind Turbine Generating High Output Power with Wind-Lens Technology. Energies, 3, 634-649. https://doi.org/10.3390/en3040634

[4] Uchida, T. and Ohya, Y. (2008) Micro-Siting Technique for Wind Turbine Generators by Using Large-Eddy Simulation. Journal of Wind Engineering \& Industrial Aerodynamics, 96, 2121-2138. https://doi.org/10.1016/j.jweia.2008.02.047

[5] Japan Meteorological Business Support Center (JMBSC). http://www.jmbsc.or.jp/english/index-e.pdf

[6] Kyoto University GPV Data Distribution Site. http://database.rish.kyoto-u.ac.jp/arch/jmadata/gpv-original.html 
[7] Kyozuka, Y., Sueyoshi, M., Hu, C. and Ohya, Y. (2014) Demonstration Experiment of Offshore Wind Power Generation by a Hexagonal Floating Platform in Hakata Bay. Proceedings of 2 nd Asian Wave and Tidal Energy Conference (AWTEC-2014), Tokyo, 28 July 2014, 133-139.

[8] Hu, C., Sueyoshi, M., Liu, C., Kyozuka, Y. and Ohya, Y. (2013) Numerical and Experimental Study on a Floating Platform for Offshore Renewable Energy. Proceedings of the 32nd International Conference on Ocean, Offshore and Arctic Engineering (OMAE 2013), Nance, 9-14 June 2013.

[9] Burton, T., Jenkins, N., Sharpe, D. and Bossanyi, E. (2011) Wind Energy Handbook. 2nd Edition, John Wiley \& Sons, Inc., Chichester.

https://doi.org/10.1002/9781119992714

[10] Ernst, B. and Seume, J. (2012) Investigation of Site-Specific Wind Field Parameters and Their Effect on Loads of Offshore Wind Turbines. Energies, 5, 3835-3855. https://doi.org/10.3390/en5103835

[11] Nissenbaum, K., Aramini, J.J. and Hanning, C.D. (2012) Effects of Industrial Wind Turbine Noise on Sleep and Health. Noise \& Health, 14, 237-243. https://doi.org/10.4103/1463-1741.102961

[12] Moeller, H. and Pedersen, C.S. (2011) Low-Frequency Noise from Large Wind Turbines. The Journal of the Acoustical Society of America, 129, 3727. https://doi.org/10.1121/1.3543957

[13] Abe, K., Kihara, H., Sakurai, A., Wada, E., Sato, K., Nishida, M. and Ohya, Y. (2006) An Experimental Study of Tip-Vortex Structures behind a Small Wind Turbine with a Flanged Diffuser. Wind and Structure, 9, 413-417. https://doi.org/10.12989/was.2006.9.5.413

[14] Takahashi, S., Hata, Y., Ohya, Y., Karasudani, T. and Uchida, T. (2012) Behavior of the Blade Tip Vortices of a Wind Turbine Equipped with a Brimmed-Diffuser Shroud. Energies, 5, 5229-5242. https://doi.org/10.3390/en5125229

Submit or recommend next manuscript to SCIRP and we will provide best service for you:

Accepting pre-submission inquiries through Email, Facebook, LinkedIn, Twitter, etc. A wide selection of journals (inclusive of 9 subjects, more than 200 journals)

Providing 24-hour high-quality service

User-friendly online submission system

Fair and swift peer-review system

Efficient typesetting and proofreading procedure

Display of the result of downloads and visits, as well as the number of cited articles

Maximum dissemination of your research work

Submit your manuscript at: http://papersubmission.scirp.org/

Or contact jfcmv@scirp.org 